\title{
Face mask resuscitation: does it lead to gastric distension?
}

\author{
H VYAS, A D MILNER, AND I E HOPKIN \\ Department of Child Health, Neonatal Unit, City Hospital, Nottingham
}

SUMMARY Inflation and oesophageal pressures were recorded simultaneously during bag and mask resuscitation of 9 asphyxiated babies. After half a minute of standard inflation pressures, higher pressures were applied for at least 5 inflations by occluding the blow-off valve. No air entered the oesophagus until a high mean inflation pressure of $5.4 \mathrm{kPa}$ was exceeded. These findings were confirmed in 4 fresh stillborn babies studied similarly. We conclude that resuscitation using bag and mask, applying pressures less than $3.5 \mathrm{kPa}$, should not lead to gastric distension.

In modern neonatal practice, ventilation of lungs with an oxygen-rich gas mixture, administered via an endotracheal tube, has become a routine procedure. However, endotracheal intubation requires considerable expertise and damage to the vocal cords can occur. Bag and mask ventilation overcomes these problems. ${ }^{1}$ The main worry about this form of therapy is that air may pass down the oesophagus, leading to gastric distension, causing splinting of the diaphragm, and adversely affecting lung expansion. Passage of a nasogastric tube is thus recommended to decompress the stomach, although this procedure itself may induce apnoea and bradycardia. Our present study was therefore set up to assess the pressure required to 'open' the oesophagus, allowing the passage of air into the stomach, by simultaneously measuring face mask and oesophageal pressures in both asphyxiated and stillborn babies.

\section{Method and technique}

All the asphyxiated babies were studied in the same manner. The baby was placed on our own modified Vickers resuscitaire. Standard criteria were used for resuscitation; that is, apnoea, heart rate of less than $100 /$ minute and falling, hypotonia, and no response to skin stimulation or oropharyngeal suction. A Gaeltec micropressure transducer, mounted near the tip of a 6 FG catheter, was passed transnasally so that the transducer lay in the lower third of the oesophagus. A modified Laerdal bag was used for face mask resuscitation. This has a pressure-limiting, blow-off valve set at $3.5 \mathrm{kPa}\left(35 \mathrm{cmH}_{2} \mathrm{O}\right)$. Pressure on the blow-off valve results in higher inflation pressures being provided at the mask. The face mask had a soft rubber rim which, when in contact with the fluid around the baby's face, minimised leaks. A 21 gauge butterfly needle was introduced high into the face mask to record inflation pressure. This was recorded using a strain gauge pressure transducer. Oxygen, at the rate of 3 litres/minute, was fed into the reservoir producing an oxygen concentration of up to $65 \%$.

The face mask was gently placed over the baby's face and the bag squeezed at a rate of 30-40/minute, each inflation lasting about 500 milliseconds. After about half a minute of ventilation, the blow-off valve was obstructed for at least 5 inflations, producing higher pressures. Normal resuscitation was continued until the baby's own respiration was adequate. The stillborn babies were studied in a similar manner, except that in one baby the blow-off valve was obstructed throughout the procedure. The signals from the transducers were transferred to an FM recorder, simultaneously displayed on an oscilloscope, and calibrated at the end of the study. $^{2}$

Data analysis. The signals from the tape recorder were subsequently fed on to ultraviolet-sensitive paper. The passage of air from the face mask into the oesophagus was indicated by a sudden, sharp increase in the oesophageal pressure tracing, either coinciding with the inflation or following it. There has often also been a shift in the oesophageal pressure baseline due to air entering the oesophagus (Figure).

Passive transfer of pressure across the mediastinal structures was easy to differentiate from these. 


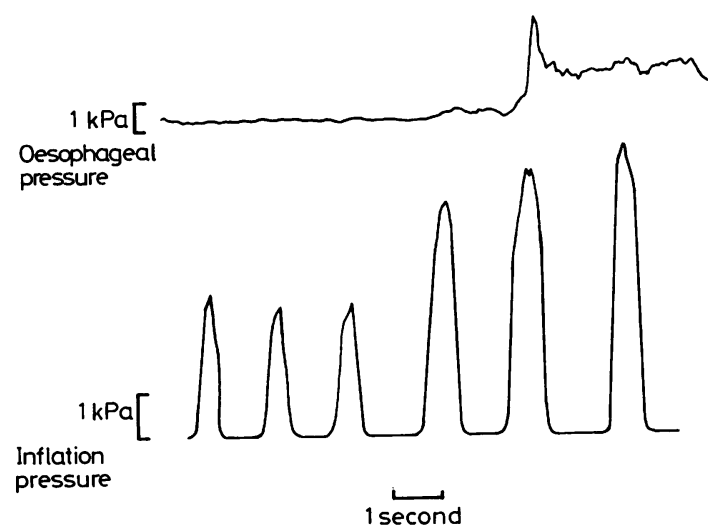

Figure Trace of oesophageal and inflation pressure during face mask resuscitation. On the fifth inflation there is a sudden increase in the oesophageal pressure. Entry of air into the oesophagus results in a baseline shift.

Subjects. Four fresh stillborn babies (heart rate present less than 6 hours before delivery) were studied within 2 hours of delivery. One was at 29 weeks, the others at 40 weeks' gestation. Birthweight ranged from 0.87 to $3.84 \mathrm{~kg}$. Of the liveborn babies, one baby was a 34-week, preterm delivery, the rest being delivered at term. Their birthweights ranged from 1.96 to $3.8 \mathrm{~kg}$.

\section{Results}

The Table summarises the results on the stillborn and liveborn resuscitated babies. The highest pressure at which air failed to enter the oesophagus was $7.7 \mathrm{kPa}\left(78 \mathrm{cmH}_{2} \mathrm{O}, 1 \mathrm{kPa} \bumpeq 10 \mathrm{cmH}_{2} \mathrm{O}\right)$ in the liveborn babies. In one stillborn baby (Case 2), air was first seen to enter the oesophagus on the fourth inflation at a pressure of $4.2 \mathrm{kPa}$. In a further baby (Case 3), an inflation pressure of $5.6 \mathrm{kPa}$ was required to produce an initial opening of the oesophagus. Subsequently, air could enter at pressures down to $2 \cdot 1 \mathrm{kPa}$. No air entered the oesophagus in the remaining 2 stillborn babies, despite inflation pressures of $9 \cdot 2$ and $5 \cdot 3 \mathrm{kPa}$.

In liveborn babies who required resuscitation, no air entered until a high mean inflation pressure of $5.4 \mathrm{kPa}$ was exceeded. This indicates that using the Laerdal bag without manual occlusion of the blowoff valve it is very unlikely for significant volumes of air to enter the stomach.

In 7 subsequent babies who required face mask resuscitation, we were unable to withdraw more than $5 \mathrm{ml}$ of air after passage of a nasogastric tube immediately after onset of spontaneous ventilation. In Case 11, an $x$-ray film taken for clinical reasons failed to show any gastric air bubble 30 minutes later.

\section{Discussion}

We anticipated that when air entered the oesophagus the pressure changes, as measured by the Gaeltec transducer, would closely mimic those occurring within the face mask. Our initial study of the stillborn babies showed that this did not occur. Inspection of our records, however, showed that air entry produced a sudden, sharp rise in the oesophageal pressure. We also noted that the sharp rise in pressures were often associated with a rise in

Table Details of the inflation pressures used during the study. On occasions, interpretation of the oesophageal pressure was difficult. These have been classified as equivocal

\begin{tabular}{|c|c|c|c|c|c|c|c|}
\hline \multirow[t]{2}{*}{ Case } & \multirow{2}{*}{$\begin{array}{l}\text { Highest inflation } \\
\text { pressure with no } \\
\text { air entry into the } \\
\text { oesophagus } \\
(\mathrm{kPa})\end{array}$} & \multirow{2}{*}{$\begin{array}{l}\text { 1st inflation with } \\
\text { air entry into the } \\
\text { oesophagus } \\
(k P a)\end{array}$} & \multirow{2}{*}{$\begin{array}{l}\text { Minimum } \\
\text { pressure for air } \\
\text { entry } \\
(k P a)\end{array}$} & \multirow{2}{*}{$\begin{array}{l}\text { Total no } \\
\text { of inflations }\end{array}$} & \multicolumn{2}{|c|}{ Number of inflations } & \multirow[t]{2}{*}{ Equivoca } \\
\hline & & & & & With air entry & With no air entry & \\
\hline \multicolumn{8}{|l|}{ Stillborn } \\
\hline 1 & $5 \cdot 3$ & 一 & - & 24 & 0 & 24 & 0 \\
\hline 2 & $6 \cdot 2$ & $4 \cdot 2$ & $2 \cdot 1$ & 50 & 5 & 45 & $\mathbf{0}$ \\
\hline 3 & $3 \cdot 6$ & $5 \cdot 6$ & $3 \cdot 6$ & 46 & 25 & 21 & 0 \\
\hline 4 & $9 \cdot 2$ & - & - & 33 & 0 & 33 & 0 \\
\hline Mean & $6 \cdot 1$ & $4 \cdot 9$ & $2 \cdot 8$ & & & & \\
\hline \multicolumn{8}{|l|}{ Liveborn } \\
\hline 5 & $6 \cdot 7$ & $4 \cdot 7$ & $3 \cdot 5$ & 21 & 1 & 17 & 3 \\
\hline 6 & $3 \cdot 1$ & $2 \cdot 4$ & $2 \cdot 4$ & 35 & 22 & 11 & 2 \\
\hline 7 & $6 \cdot 1$ & $5 \cdot 5$ & $4 \cdot 4$ & 20 & 2 & 13 & 5 \\
\hline 8 & $7 \cdot 7$ & $6 \cdot 1$ & $4 \cdot 4$ & 67 & 19 & 48 & 0 \\
\hline 9 & 6.6 & $6 \cdot 6$ & $3 \cdot 3$ & 35 & 9 & 26 & 0 \\
\hline 10 & $7 \cdot 5$ & $7 \cdot 5$ & $3 \cdot 4$ & 45 & 16 & 26 & 3 \\
\hline 11 & $7 \cdot 5$ & $8 \cdot 3$ & $3 \cdot 1$ & 52 & 2 & 47 & 3 \\
\hline 13 & $6 \cdot 4$ & $3 \cdot 6$ & $3 \cdot 5$ & 28 & 6 & 18 & 4 \\
\hline Mean & $6 \cdot 4$ & $5 \cdot 4$ & $3 \cdot 1$ & & & & \\
\hline
\end{tabular}


the oesophageal baseline pressure, probably due to gaseous distension.

This type of measurement did not allow us to estimate the amount of air passing down the oesophagus when high inflation pressures were used, but, in 7 subsequent babies, we have been unable to aspirate more than $5 \mathrm{ml}$ of air at the end of a standard face mask resuscitation.

Using this approach, we found that there was only one baby in whom we could identify any air entry at pressures likely to be achieved during standard face mask resuscitation. The mean inflation pressure at which passage of air occurred was $5.4 \mathrm{kPa}$, although, subsequently, air entered at pressures as low as $2 \cdot 1 \mathrm{kPa}$. However, even with high inflation pressures, air entry was often intermittent. The figures obtained in 2 of the 4 stillborn babies were similar but, in the remaining 2 , no air entry occurred despite high inflation pressures exceeding $9 \mathrm{kPa}$.

Our findings suggest that the opening pressure of the oesophagus, to a rapidly rising 500 millisecond inflation, is indeed higher than that of the lungs. ${ }^{3}$ The difference in the two could be explained by the fact that the oesophagus is a highly compliant organ and is most likely to be partially collapsed with cohesion of the moist mucosal surfaces.

Previous reports on this subject are sparse. Ruben et al., ${ }^{4}$ investigating 20 anaesthetised adults, using a face mask, found that the cardia acts as a 'pressuresensitive valve' and in most cases opened at between 1.5 and $2.5 \mathrm{kPa}$. Hull ${ }^{5}$ reported volumes of gas entering the stomach in 6 asphyxiated babies who had their endotracheal tubes misplaced into their oesophagus. He found that the resistance of the oesophagus was similar to, or greater than, that of the lungs. However, the presence of an endotracheal tube in the oesophagus is more likely to lead to air entry into the stomach than when the same pressure is applied only at the mouth.

Gastric distension often occurs with facial continuous positive airways pressure (CPAP) or face mask ventilation. However, this is not akin to face mask resuscitation at birth. Firstly, during CPAP or face mask ventilation, the baby will be swallowing continuously and thus permitting air into its stomach. Secondly, during face mask resuscitation, positive pressure is produced for a very brief period, unlike CPAP where a static positive pressure is maintained for long periods.

We conclude from our study that face mask resuscitation, using a bag and mask system, applying rapid inflations with pressures less than $3.5 \mathrm{kPa}$, should not lead to gastric distension.

We express our appreciation to Professor D Hull, and thank Mrs S Tyrrell for excellent secretarial assistance.

Financial support was provided by the Medical Research Council.

\section{References}

1 American Heart Association. Basic life support in infants and children. $J A M A 1980 ; 244: 472-8$.

2 Vyas H, Milner A D, Hopkin I E. Intrathoracic pressure and volume changes during the spontaneous onset of respiration in babies born by caesarean section and by vaginal delivery. $J$ Pediatr 1981; 99: 787-91.

3 Boon A W, Milner A D, Hopkin I E. Physiological responses of the newborn infant to resuscitation. Arch Dis Child 1979; 54: 492-8.

4 Ruben H, Knudsen E J, Carugati G. Gastric inflation in relation to airway pressure. Acta Anaesthesiol Scand 1961; 5: 107-14.

5 Hull D. Asphyxia neonatorum. In: Gairdner D, Hull D, eds. Recent advances in paediatrics, fourth edition. Churchill, 1971: 79-80.

Correspondence to Professor A D Milner, Queen's Medical Centre, Department of Child Health, E Floor, East Block, Clifton Boulevard, Nottingham NG7 2UH.

Received 18 January 1983 